\title{
O SIGNIFICADO DE SER ESPECIALISTA PARA O ENFERMEIRO ESTOMATERAPEUTA
}

\author{
Maria Angela Boccara de Paula ${ }^{1}$ \\ Vera Lúcia Conceição de Gouveia Santos²
}

Paula MAB, Santos VLCG. O significado de ser especialista para o enfermeiro estomaterapeuta. Rev Latino-am Enfermagem 2003 julho-agosto; 11(4):474-82.

Este estudo teve como objetivo conhecer e compreender as percepções dos estomaterapeutas em relação aos significados de ser especialista, tendo como referencial metodológico a Teoria das Representações Sociais. A análise dos discursos de 12 estomaterapeutas permitiu significar três Unidades Temáticas: o estomaterapeuta como profissional, pessoa e junto ao cliente. Representações principalmente positivas como valorização, reconhecimento, remuneração, ascensão, satisfação, vontade de crescer, destaque profissional, melhoria da qualidade da assistência e segurança do cliente foram desveladas para os enfermeiros em relação à Estomaterapia. Algumas significações negativas como cobrança e falta de reconhecimento também surgiram. Essas representações indicaram a especialização como importante dimensão no percurso profissional, fato que tem influenciado positivamente o caminhar do enfermeiro em particular do estomaterapeuta. Esse constrói sua existência no tempo, escreve sua história impulsionada para a ação autônoma e com credibilidade, que permite a conquista de espaço e a resignificação do cuidar - fundamento da arte e ciência da Enfermagem.

DESCRITORES: enfermagem; ostomia; papel profissional

\section{THE MEANING OF SPECIALIZATION FOR THE ENTEROSTOMAL THERAPIST}

This study aimed at knowing and understanding the meanings and perceptions of the enterostomal therapist (ET) about this specialty, using the methodological framework of Social Representation Theory. Three major Units were identified: the ET as a professional, the ET and the client, the ET as a person from an analysis of 12 ET's discourse. In relation to Enterostomal therapy, mainly positive representations were identified among nurses, such as: valorization, recognition, remuneration, promotion, satisfaction, ambition, professional prominence, improvement of care quality and client safety. On the other hand, demands and lack of recognition emerged as negative representations. These representations indicate specialty as an important dimension in professional evolution, a fact that has positively influenced the career of the nurse and that of the Enterostomal Therapist in particular. The ET's construct their existence, write their own history, driven towards autonomous and credible action, which allows them to conquer their space and give a new meaning to care - the basis of Nursing art and science.

DESCRIPTORS: nursing; ostomy; professional role

\section{EL SENTIDO DE SER ESPECIALISTA PARA EL ENFERMERO ESTOMATERAPEUTA}

Este estudio tuvo como objetivo conocer y comprender las percepciones de los estomaterapeutas en relación con el sentido de ser especialista, tiendo como referencial metodológico la Teoría de las Representaciones Sociales. El análisis de los discursos de 12 terapistas enterostomales (ET) permitió significar tres Unidades Temáticas: el TE como profesional, persona y junto al cliente. Representaciones principalmente positivas como valoración, reconocimiento, remuneración, ascensión, satisfacción, ganas de crecer, realce profesional, mejora de la calidad de la atención y seguridad del cliente, fueron desveladas por los enfermeros en relación a la Terapia Enterostomal. Algunas significaciones negativas como cobranza y falta de reconocimiento también surgieron. Esas representaciones indicaran percepciones de la especialización como importante dimensión en el trayecto profesional que tiene influenciado positivamente el caminar de lo TE. Este construye su existencia en el tiempo, escribe su historia impulsando la acción autónoma y con credibilidad, que permite la conquista del espacio y la resignificación del cuidar - fundamento de la arte y ciencia de la Enfermería.

\section{DESCRIPTORES: enfermería; ostomía; rol profesional}

\footnotetext{
${ }^{1}$ Mestre em Enfermagem pela Escola de Enfermagem da Universidade de São Paulo, Professor Assistente, Coordenador do Curso de Especialização em Estomaterapia da Universidade de Taubaté, e-mail: boccaradepaula@ig.com.br; ${ }^{2}$ Doutor em Enfermagem, Professor Doutor, Coordenador do Curso de Especialização em Estomaterapia da Escola de Enfermagem da Universidade de São Paulo, e-mail: veras@usp.br
} 
INTRODUÇÃO

$\boldsymbol{A}$ especialidade estomaterapia surgiu no final da década de 50, nos EUA, onde também ocorreram as primeiras e mais simples formas de treinamento, sucedidas dos cursos formais, sendo, no entanto, reconhecida como exclusiva do enfermeiro apenas em 1980, pelo World Council of Enterostomal Therapists (WCET). No Brasil, a especialidade foi precedida por movimentos profissionais e de ostomizados e sedimentouse, de fato, a partir da realização do primeiro curso de especialização que ocorreu em 1990, na Escola de Enfermagem da Universidade de São Paulo ${ }^{(1)}$.

A escolha de uma especialidade profissional caracteriza-se como importante momento de transformação pessoal e social, impregnada de simbolismos e significações individuais e coletivas, não constituindo, portanto, uma opção tão simples e fácil como pode parecer. É multidimensional, complexa e plurideterminada por inúmeros fatores pessoais, sociais, filosóficos, políticos e econômicos, dentre outros ${ }^{(2)}$.

Na saúde, as profissões também caminham, diaa-dia, para a especialização do saber e do cuidar, à medida que novos conceitos e tecnologias são desenvolvidos, abrindo-se, como conseqüência, novos campos de atuação e pesquisa.

Visto que a história da Enfermagem está intimamente relacionada à história da Medicina, tem sido muito difícil compreender e conceituar as suas relações, especialmente no que diz respeito à dependência entre ambas as profissõos ${ }^{(3)}$, o que acontece também em relação às especializações.

Em nosso país, após a reforma universitária de 1968, a Medicina passou a preconizar o ensino baseado em sistemas e órgãos isolados do corpo, contribuindo para um modelo de especialidade fragmentado, monopolizado e precocemente gerido na formação acadêmica ${ }^{(4)}$. Desse modo, a idéia de expert- aquele que domina uma parte do todo - passou a ser bastante valorizada na sociedade, sustentando o mito da eficácia e racionalidade técnica e tornando-se um sistema de referência, particularmente na área médica. Esses sistemas de referência "são imagens que condensam um conjunto de significações, que nos permitem interpretar o que acontece conosco e até dar um sentido ao inesperado. São categorias que servem para classificar as circunstâncias, os fenômenos e os indivíduos com que nos relacionamos, são teorias que permitem estabelecer opiniões sobre eles" ${ }^{\text {"(5) }}$, ou seja, são as representações subjetivas dos sujeitos que permeiam o processo de construção do conhecimento.

$\mathrm{Na}$ Enfermagem, embora influenciada pelas especializações médicas, tal escolha não é, no entanto, tão precocemente determinada como na Medicina, o que se justifica pela própria história da profissão.

O surgimento da Enfermagem Moderna decorreu da divisão do trabalho médico. À medida que inúmeras atividades auxiliares foram se incorporando aos serviços médicos, sobrecarregando o profissional, todo o trabalho direto da assistência ao doente, ou seja, as tarefas ditas manuais, passaram a constituir, aos poucos, atribuições da Enfermagem ${ }^{(3)}$. Assim, o médico "delegou" para a enfermagem o "cuidar", um trabalho considerado menos "nobre" e que demandava tempo.

No contexto das profissões da saúde, a Enfermagem ocupa posição ímpar, pois é numericamente significativa dentro das instituições, quase que exclusivamente feminina, assalariada e hospitalar, desenvolvendo atividades centradas no cuidado em saúde de pessoas. Enquanto "cuidar é tarefa de mulher enfermeira; tratar é tarefa de homem - médico"(6). Além disso, a divisão do trabalho em tarefas e procedimentos caracteriza sua modalidade funcional. Essa divisão técnica e social do processo de trabalho, organizado nas diferentes categorias profissionais que hoje compõem a equipe de Enfermagem - de formação escolar e social heterogênea - tem, no saber legitimado, o "monopólio" do enfermeiro que passa, então, a realizar o trabalho mais "intelectual" da profissão, assumindo funções de gerenciamento e supervisão, com poder de dominação e controle do pessoal subalterno que, por sua vez, realiza o trabalho dito "mais simples", manual. A conseqüência dessa divisão do saber e do trabalho é o distanciamento gradativo do cuidar, objeto original de ação, por parte do enfermeiro ${ }^{(3,7-9)}$.

Nessa trajetória profissional, a década de 70 foi marcada pelas teorias e teoristas de Enfermagem que procuravam construir um corpo específico de conhecimentos, caracterizando-se como importante 
momento de busca do reconhecimento social ${ }^{(7)}$ e de representação mais positiva da profissão. Esse conhecimento em ascensão e os concomitantes e constantes avanços tecnológicos e científicos, aliados às novas exigências dos usuários e dos serviços de saúde, contribuíram para impulsionar o crescimento e desenvolvimento das especialidades de Enfermagem, as quais encontram, ainda hoje, elementos que as favorecem e as justificam como o custo - efetividade, custo - utilidade e a qualidade dos serviços prestados ${ }^{(1,9)}$.

Embora as especialidades profissionais constituam um fato, trazem, em seu bojo, inúmeros desafios relacionados à maior demanda de consumidores mais conscientes de seus direitos e, portanto, à maior responsabilidade profissional. Paralelamente, as políticas públicas, ao implicarem em seleção de elementos, qualidade do cuidado e custos, colocam os profissionais no centro de um labirinto de difícil saída ${ }^{(10)}$. Quanto ao desenvolvimento tecnológico constante, se por um lado amplia o campo de atuação do profissional, por outro, pode repercutir negativamente na prática diária, ao passar a ser visto como produto final da assistência, desumanizando-a ${ }^{(11)}$. Algo como a "sensação de habitarmos um mundo quebrado, onde as relações humanas fazem-se cada vez mais difíceis". Pode-se afirmar, então, que a verticalização e fragmentação do saber e a visão não holística do ser humano constituem os aspectos primordiais desses conflitos, impondo-se a necessidade do estabelecimento de um ponto de equilíbrio entre ambos, que possa garantir uma assistência humanitária e científica adequada.

Buscando significar o especialista enfermeiro, o International Council of Nurses (ICN) conceitua-o como aquele preparado no nível de uma enfermagem generalista e autorizado a praticar, como um especialista, com avançado domínio em um raro campo da enfermagem. Inclui papéis clínico, de ensino, administrativo, de pesquisa e consultoria ${ }^{(1)}$. Já, o conceito de especialista proposto por Benner ${ }^{(12)}$ descreve o enfermeiro especialista como aquele que domina as múltiplas dimensões estabelecidas pelas teorias, garantindo os limites da flexibilização do seu uso frente às reais necessidades do cliente por meio da intuição, raciocínio e experiências advindas da própria clientela, ou seja, introduz a subjetividade como uma das bases do cuidar em Enfermagem.
O enfermeiro especialista em estomaterapia ou estomaterapeuta (ET) é definido como aquele que possui conhecimentos, treinamento específico e habilidades para o cuidado dos clientes ostomizados, portadores de feridas agudas e crônicas, fístulas e incontinência anal e urinária $^{(1,13)}$.

Apesar de possuir um vasto e amplo campo de atuação, o ET ainda enfrenta inúmeras dificuldades para exercer realmente a sua prática especializada. Essas, mais uma vez, certamente têm origem não só na história da Enfermagem, mas também na formação atual do enfermeiro, no desempenho diário e rotineiro de suas atribuições, nos mecanismos de poder institucional sobre o profissional e na própria imagem do enfermeiro vigente na sociedade brasileira e mesmo institucional.

A "dupla" vivência como enfermeiros generalistas e especialistas, "profissões" que ora se imbricam ora se ajustam, além da participação ativa na Enfermagem, em especial da Enfermagem em Estomaterapia, levou-nos a refletir sobre essa prática especializada. Impõe-se desvendar significados sobre o ser especialista e avaliar o que efetivamente se reorganiza e o que se incorpora na vida dos profissionais após a especialização. Compreender, enfim, por que os enfermeiros buscam e efetivam a prática da formação especializada e continuam com o duplo/único papel de enfermeiros e especialistas, apesar das inúmeras dificuldades. Esses questionamentos compõem os objetivos desta investigação, quais sejam, conhecer e compreender as percepções dos enfermeiros ETs em relação aos significados de ser especialista.

\section{PROCEDIMENTOS METODOLÓGICOS}

Para realizar este estudo, optou-se pelo enfoque qualitativo à luz da teoria das Representações Sociais (RS).

As metodologias qualitativas são "aquelas capazes de incorporar a questão do significado e da intencionalidade como inerentes aos atos, às reações e estruturas sociais, sendo essas últimas tomadas, tanto em seu advento quanto na sua transformação, como construções humanas significativas"(14). Enfocam, portanto, o universo de significados, motivos, aspirações, 
crenças, percepções, valores e atitudes que permeiam as relações, dando ênfase a essas, e não somente ao resultado/produto, o que corrobora a justificativa do enfoque escolhido.

Quanto à teoria das RS, estuda a cultura e os fenômenos de um grupo específico e os processos imaginários de seus integrantes, sendo, assim, uma produção simbólica, expressão dos sentidos e percepções que as pessoas têm dessa realidade ${ }^{(15)}$.

Essas representações, mesmo que particulares, expressam os significados atribuídos pelo grupo ao qual pertencemos e, portanto, representações coletivas, uma vez que fazem parte da rede de relações que se tornam sociais, por meio do pessoal e vice-versa, num processo dinâmico de construção e transformação do cotidiano ${ }^{(10)}$.

A profundidade de uma representação e sua carga simbólica estão intimamente relacionadas com a comunicação que se dá no interior da sociedade; desse modo, é social, à medida que é comunicativa, conversacional, dialógica ${ }^{(16)}$, ou seja, é resultado da interação entre o indivíduo e o meio em que vive, e viceversa, repercutindo de forma intensa e determinante na trajetória dos elementos que a compõem.

O enfermeiro estomaterapeuta, embora como ser singular que tem percepções particulares, está inserido em um determinado contexto histórico-social e, portanto, faz parte de uma sociedade, num momento específico. Compõe e participa de um grupo que possui e "faz" a sua história. Assim, mesmo que particulares, os seus significados refletem representações coletivas, uma vez que o sujeito nelas expressa o sentido que dá à sua experiência no mundo social, a partir de referências individuais e de acordo com o contexto de valores culturais e sociais $^{(10)}$, vindo, portanto, ao encontro do objetivo desta investigação.

Sujeitos

Fizeram parte desta investigação doze enfermeiras ETs, formadas há, pelo menos, dois anos. A idade variou de trinta e um a quarenta e sete anos (média de 28,5 anos); sendo nove residentes em São Paulo (quatro na capital e cinco no interior) e três de outros estados. O tempo de graduação em Enfermagem variou de onze a dezenove anos (média de 13,7 anos), e de dois a oito anos (média de 5,1 anos) como especialistas. Todas atuam junto a pacientes com ostomias, dez também com portadores de feridas e apenas duas atuam nas três áreas da especialidade, ostomias, feridas e incontinências.

Coleta e análise dos dados

Os dados foram coletados por meio de entrevistas individuais, norteadas pelo questionamento: "O que significa ser enfermeiro especialista em estomaterapia para você, hoje?"

Os entrevistados foram orientados acerca dos objetivos do estudo e, após aceitarem participar do mesmo, assinaram um termo de consentimento. As entrevistas foram realizadas na cidade de São Paulo, em abril e maio de 1999, em três diferentes momentos, que foram eleitos por se tratarem de reuniões científicas da especialidade, que congregavam profissionais de diversas localidades do país, caracterizando-se, assim, numa oportunidade ímpar de acesso a esses colegas.

Os depoimentos então obtidos foram submetidos à análise de conteúdo, visto que, tudo o que é dito ou escrito é susceptível de ser submetido a uma análise de conteúdo ${ }^{(17)}$, cujo objetivo principal é a compreensão crítica do sentido das comunicações, a busca das significações explícitas ou ocultas, manifestas ou latentes ${ }^{(18)}$.

A análise de conteúdo constou de uma etapa inicial onde os discursos foram pré- analisados, por meio de inúmeras leituras do material coletado, com assinalamento dos dados de interesse para a investigação. Esses fragmentos de discursos foram, então, submetidos a uma categorização inicial que, após interpretação à luz do referencial teórico-metodológico, objetivos e idéia-base, passaram a compor a categorização final, em três grandes Unidades Temáticas: o ET como profissional, o ET e o cliente e o ET como pessoa e seus respectivos subtemas.

\section{SIGNIFICANDO O SER ESPECIALISTA EM ESTOMATERAPIA}

As Unidades Temáticas resultantes da análise dos discursos obtidos permitiram desvendar significados e representações acerca do ser especialista para o enfermeiro estomaterapeuta, os quais passamos a descrever e discutir. $\mathrm{O}$ esquema representacional das Unidades Temáticas está contido na Figura 1. 


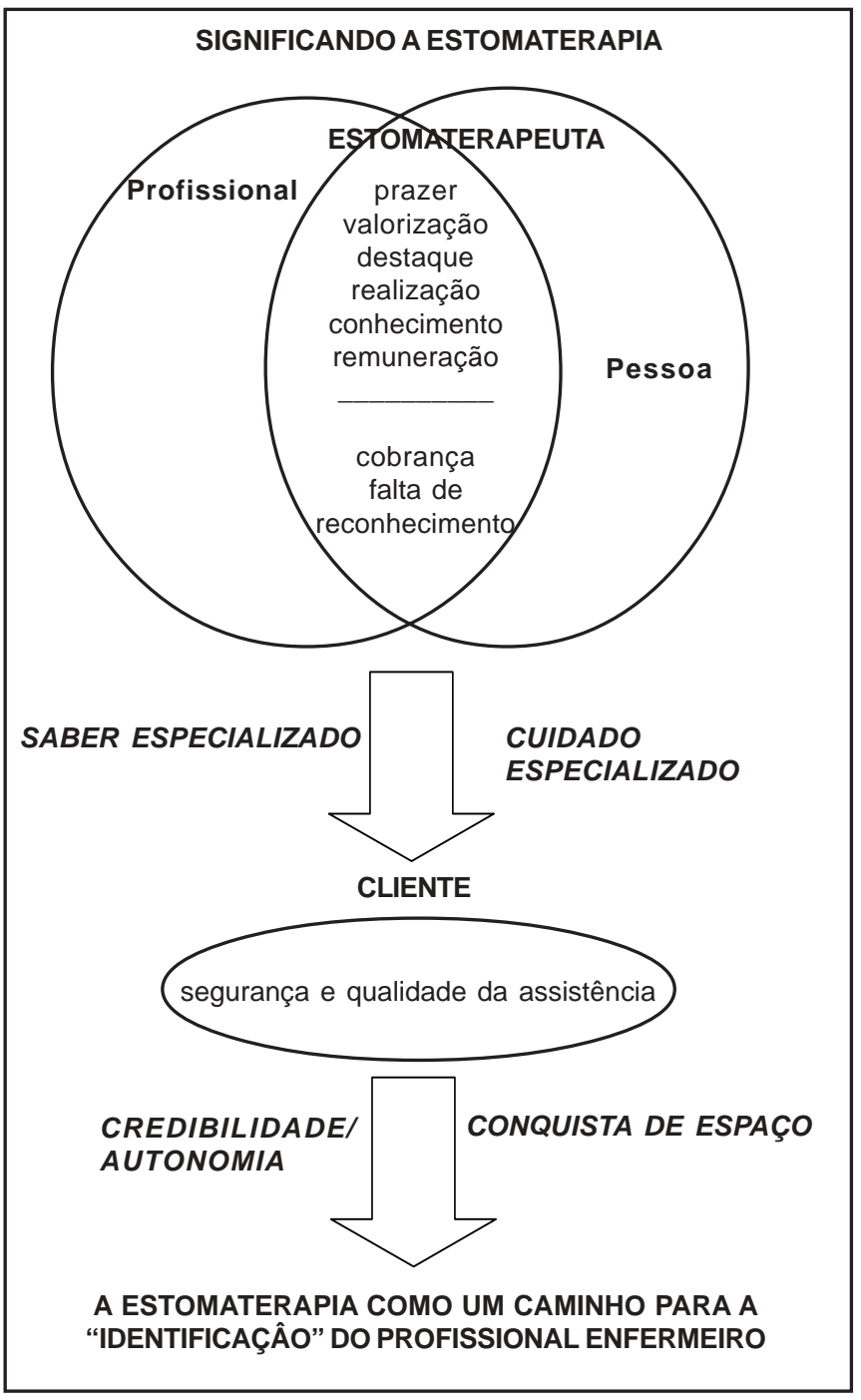

Figura 1 - Significado de ser especialista em estomaterapia

Unidade temática I: o estomaterapeuta como profissional

Identificar os significados de ser estomaterapeuta profissional e torná-los explícitos é importante para se conhecer o especialista, suas conquistas, ansiedades e perspectivas. "O caráter simbólico e imaginativo dos saberes sociais envolvem a dimensão dos afetos, porque os sujeitos sociais empenham-se em dar sentido ao mundo, também com emoção, com sentimento e com paixão" ${ }^{\prime 16)}$.

A Unidade, que tem como tema o ET como profissional, engloba inúmeras representações positivas acerca do especialista e suas novas relações com e no trabalho

e recon represe de papéis na equipe de saúde. Sentir-se útil, valorizado, reconhecido pelo grupo profissional, equipe de saúde e clientela, traduz-se em percepções e sentimentos que envolvem a personalização do profissional, isto é, sua identidade reconhecida que tem, no saber específico, um importante elemento de diferenciação, especialmente no contexto da própria profissão.

... Caminhos melhores direcionados fazem com que 0 profissional se valorize mais, tenha maior valor diante da sociedade, diante do grupo, diante das pessoas.

A especialização, ao permitir um caminho melhor direcionado, leva o ET a encontrar reconhecimento, satisfação e prazer profissional, na sua prática diária. Esse agir diferente - diferenciado, com conhecimento, posiciona-o de forma única dentro da equipe de trabalho e permite ainda que lutas e objetivos comuns da especialidade sejam resgatados na concretude dessa prática.

... me satisfaz a parte pessoal, profissional, de ter uma especialidade que poucas pessoas têm, e que me faz agir de forma diferente. Então há satisfação...

A posição de destaque em que o enfermeiro especialista se percebe, por sentir-se único, identificado, necessário e útil, caracteriza uma RS, fruto da percepção e desejo individuais que se tornam concretos no social e vice-versa.

... antigamente eu estava ali, num setor e... eu era apenas mais uma.

... todos os hospitais me conhecem.

Outro aspecto bastante enfatizado pelos ETs, na esfera profissional, foi a busca constante e a necessidade de capacitação técnica, revelando-se como aspecto imprescindível e fundamental para a construção da identidade e espaço profissionais do enfermeiro e contribuindo também, de forma bastante intensa e positiva, para a renovação e a produção científica.

...uma busca constante, incansável, sempre buscando conhecimentos...

A resignificação da profissão e da imagem profissional em que se encontra a Estomaterapia, por meio das mudanças de comportamento e percepções, descortinam novas possibilidades de atuação, novos caminhos que levam ao crescimento pessoal e profissional.

... a estomaterapia fez com que a gente mudasse a forma de pensamento, de avaliação... Fez com que a gente tenha um pensar diferente.

O crescimento traduzido pela ascensão 
profissional, possível graças à especialização, ratifica o saber especializado como elemento que viabiliza novas e maiores oportunidades, que gera um olhar diferente por parte da sociedade e da categoria em relação à profissão, que leva a conquistas de espaços e novas percepções, e que impulsiona o especialista a novos e desafiadores caminhos e oportunidades profissionais.

... fui convidada para trabalhar na empresa, representou toda uma mudança que teve, inclusive... ascensão profissional.

Outro aspecto bastante interessante, embora conflitante e contraditório, esteve relacionado à Enfermagem generalista \&/X especializada. Os discursos que seguem podem exemplificar tais conflitos e contradições:

... parece que a gente quer ter domínio exclusivo de uma área que todo mundo se julga capaz de fazer...

... talvez ser generalista seja muito cômodo, eu sei de tudo um pouco, mas ninguém me cobra o máximo, por coisa alguma.

Esses depoimentos refletem a forma fragmentada com que a assistência de enfermagem se organizou, desde sua origem, na divisão técnica do trabalho e do ensino fundamentado em órgãos e sistemas, do papel burocrático-gerencial do enfermeiro nas inúmeras funções e atividades acumuladas após a especialização, e nas várias adequações e readaptações necessárias para transformar a prática pós-especialização.

Essa prática marcada pelo cuidar especializado \&/X o cuidar generalista subsidia o especialista para a busca de formas de desempenho não só de novas funções como para a qualificação das antigas. Ao destacar-se, no entanto, provoca situações desagradáveis e dificuldades nas relações com os demais enfermeiros. Tais conflitos ultrapassam as diferenças de conhecimentos ao envolverem aspectos importantes relativos ao baixo comprometimento do enfermeiro com a própria classe profissional.

... dentro da instituição a gente vê isso, que as pessoas vêem a gente com um pouco de inveja...

A presença da palavra "inveja", nos discursos obtidos, pode caracterizar sentimentos como o medo e o ressentimento por parte dos outros elementos da equipe, sendo percebidos pelo especialista como um desafeto, agressão e/ou incompreensão.

... algumas pessoas vêem como se a gente quisesse ser melhor...

O distanciamento do objeto de trabalho - o cuidar - por parte do enfermeiro generalista e uma possível acomodação em relação aos significados e representações da profissão, já incorporados, podem ser identificados como mecanismos sociais de defesa, na tentativa de diminuir a angústia, aliviar a culpa, justificar sua posição, dentre outros, assim como o próprio sentimento de isolamento, que alguns profissionais especialistas manifestam.

Nova conquista, também apontada nos discursos relacionados ao papel profissional, é a possibilidade de remuneração pela prestação direta de serviços, permitindo que a atividade autônoma do profissional se concretize. Novamente, o reconhecimento pelo trabalho realizado encontra, no saber especializado, um dos elementos diferenciadores.

... daí eu tinha paciente particular... eu fazia atendimento particular recebendo.

O aspecto relacionado ao repasse de conhecimentos parece ser uma realidade para o ET, através do qual estabelece não só a ponte entre a teoria e a prática, como desempenha o papel de educador, inerente ao enfermeiro e à prática especializada, alargando as fronteiras de atuação e propiciando a melhoria da qualidade da assistência prestada.

A gente tem de estar treinando, de estar passando este conhecimento para os colegas, de fazer com que o pessoal consiga ver a especificidade do cuidar.

Alguns aspectos negativos também foram apontados como o aumento de cobrança, tanto em nível institucional - que gera a sobrecarga de trabalho - como em nível pessoal- em função das auto-exigências. Frente ao pequeno número de cursos e de profissionais existentes no país, surge a necessidade de superação, movida pelo desejo comum dos especialistas em contribuírem para o crescimento e desenvolvimento da especialidade.

De certa forma com cobrança..., eles me cobram....

... a gente vê um aumento de responsabilidade maior, não só do lado profissional, mas pessoal também.

A falta de reconhecimento institucional, como mais um aspecto negativo apontado, contribui para o isolamento do especialista, decorrente não só do desinteresse e incompreensão das intervenções especializadas como da restrita importância atribuída ao trabalho realizado e desconhecimento dos resultados efetivos e positivos dele advindos. Trata-se, portanto, de mais um desafio para o estomaterapeuta: poder contribuir para a resignificação de seu valor e para o reconhecimento de sua profissão na sociedade. 
... eu me posicionei onde eu trabalho, para a instituição é ainda uma coisa, assim... que não vê, não consegue perceber a diferença...

Essa Unidade Temática denota as percepções e significados profissionais atribuídos pelos ETs à especialidade, que passa a ser vista como a essência que fundamenta a sua prática profissional e o alicerce para lutar e conquistar seu espaço, mesmo quando enfrenta as dificuldades que permeiam, naturalmente, o seu desenvolvimento profissional.

Unidade temática II: o estomaterapeuta e o cliente

O cliente, integrante da sociedade e usuário dos serviços, é o principal elemento envolvido no processo de valorização e reconhecimento dos profissionais de saúde, capaz de gerar credibilidade social e influenciar, de forma determinante, no estabelecimento da identidade do especialista, a partir da avaliação da qualidade da assistência recebida.

Esta Unidade Temática traz, sob a ótica do ET, a segurança que o cliente desenvolve em relação à assistência especializada que recebe, possibilitando ao especialista conquistar a credibilidade, a confiança e espaço específico junto à clientela que dele necessite.

O desempenho eficaz do seu papel de cuidar e de coordenar a assistência, com domínio da atividade técnica e do saber solidificado, encontram, na empatia e no respeito ao ser humano, caminhos de interação, fundamentais à segurança alcançada.

... ele passa a confiar em você...

... eu não vejo necessidade de falar que sou especialista... ele vê que você conhece.

A melhoria da qualidade da assistência constitui um outro significado de destaque na percepção do ET, em sua relação com a clientela. O saber aliado ao respeito pelo ser humano, por meio da compreensão de escolhas e da interpretação dos sinais que Ihes são manifestados, possibilita o resgate da integralidade e essencialidade da pessoa, o que garante um espaço único onde o trabalho é identificado e ganha identidade, contribuindo para transformar a representação do enfermeiro pela própria categoria profissional e pela sociedade em geral.

... estou fazendo uma assistência muito humanizada, e pensando em qualidade de vida para o paciente.

As RS são categorias em constante construção e reconstrução ${ }^{(10)}$, são frutos de uma totalidade histórico- social e, dessa forma, são também frutos da nossa história individual, pessoal, em que somos sujeitos das mudanças que orientam nosso jeito de viver e de atuar e emergem de um "caminho coletivo que se faz caminhando"(19). Essa também constitui a história da estomaterapia e de seus especialistas.

Mais uma vez, nesta Unidade Temática, nota-se a presença do saber especializado como um elemento de sustentação da prática profissional, agora percebido pelo cliente - aquele para quem são desenvolvidas as atividades especializadas, desde o planejamento até a assistência e que, conseqüentemente, é o fundamento de suas ações. Encontrar retorno positivo junto à clientela é fator que estimula e incentiva o profissional a buscar a crescente melhoria da sua atuação, com o objetivo de poder não só satisfazer as demandas de cuidar especializado como as suas próprias, como pessoa.

Unidade temática III: o estomaterapeuta como pessoa

Esta Unidade inclui representações que permeiam o lado pessoal do profissional, dois lados imbricados que, dificilmente, podem ou devem ser separados. A satisfação, realização e prazer pessoal advindos da prática profissional estão intimamente relacionados com os aspectos da autonomia pessoal, fonte de auto-estima e de auto-aceitação, que viabilizam o reconhecimento concreto e a aceitação pessoal e profissional. "O trabalho não visa apenas à produção da subsistência, mas, antes de tudo, à criação da disciplina e ao resgate do valor da autonomia pessoal" ${ }^{\text {(19) }}$.

... me satisfaz a parte pessoal...

... eu me realizo fazendo isso...

A vontade de crescer destaca-se como um grande potencial entre os ETs, para os quais novas conquistas pessoais e profissionais constituem importantes elementos para a constante construção da especialidade, por meio da superação de limites. Os ETs parecem compreender que para crescer é necessário, muitas vezes, enfrentar dificuldades, ter paciência e estar disponível ao aprendizado.

... a vontade de crescer é imensa...

Profissional e pessoal são categorias em constante construção e reconstrução, que perpassam o caminhar do ser humano, durante toda a sua vida e, portanto, complementam-se e sobrepõem-se e é, dessa forma, que aparecem também nesta investigação, o que 
é possível notar nas Unidades Temáticas I e III. O trabalho é a força propulsora do homem na sociedade e, portanto, completa seu lado pessoal. A estomaterapia, enquanto especialidade profissional do enfermeiro, está auxiliando o profissional, na ótica do especialista, a unir esses dois aspectos fundamentais e complementares da vida, orientando, conseqüentemente, o "nosso jeito de viver e atuar".

Evidencia-se, então, que a especialidade está sendo construída e alicerçada na vontade pessoal de cada especialista engajado, o qual, a cada dia, enfrenta novos e diferentes desafios determinados pelo tamanho de suas ambições. É inerente ao ser humano o desejo de expandir limites, sendo preciso compreender que, para tanto, é necessário enfrentar dificuldades, ter paciência e estar disponível ao aprendizado.

\section{CONSIDERAÇÕES FINAIS}

O significado de ser especialista, resgatado pelos ETs nas três dimensões apontadas: o ET como profissional, pessoa e junto ao cliente, revela importantes interfaces entre o ser profissional e o ser pessoal que refletem sua relação e desempenho junto ao cliente e para o qual o saber e o cuidado especializado/ humanizado são importantes e fundamentais elementos em busca de novos espaços, credibilidade e autonomia. A Estomaterapia mostra-se, então, como um caminho para a "identificação" do profissional enfermeiro na sociedade de modo geral. Desse modo, apresenta-se como dimensão

\section{REFERÊNCIAS BIBLIOGRÁFICAS}

1. Santos VLCG. A bolsa na mediação estar ostomizado estar profissional:análise de uma estratégia pedagógica. [tese]. São Paulo (SP): Escola de Enfermagem/USP; 1996.

2. Cruz EMTN. Especialidade. As complexidades da escolha. Ser médico 1998; 3:16.

3. Almeida MCP, Rocha JSY. O saber de enfermagem e sua dimensão prática.São Paulo (SP): Cortez; 1986.

4. Machado $\mathrm{MH}$, coordenador. Os médicos no Brasil: um retrato da realidade. Rio de Janeiro (RJ): FIOCRUZ; 1997.

5. Jodelet $D$. Les representantatins sociales. Paris: Presses Universitaires de France; 1989.

6. Fonseca TMG. De mulher a enfermeira: conjugando trabalho e gênero. In: Lopes MJM organizador. Gênero e Saúde. Porto Alegre (RS): Artes Médicas; 1996.

7. Nakamae DD. Novos caminhos da enfermagem. São Paulo (SP): Cortez;1987.

8. Silva MAPD. As representações Sociais e as Dimensões Éticas. Taubaté (SP): Cabral Ed. Universitária; 1998. importante no contexto e percurso da profissão, certamente da mesma maneira como as demais especialidades de Enfermagem. Encontra-se num processo de encontro de novas perspectivas para o cuidar, e pauta-se no saber e objetivos comuns da especialidade e dos especialistas. Colabora na formação e desenvolvimento de um grupo de profissionais/especialistas mais coeso, forte, envolvido e preocupado com o processo de transformação, em direção ao progresso e à melhoria da qualidade da assistência prestada pelos profissionais de enfermagem, especialistas ou não, e que conquista, paulatinamente, credibilidade no contexto das profissões da saúde.

É o estomaterapeuta construindo definitivamente a sua existência no tempo, vivendo a tensão entre a utopia - que o anima a olhar sempre para cima e para frente - e a história real - que o obriga a buscar mediações, dar passos concretos e olhar com atenção para o caminho e sua direção, suas bifurcações e empecilhos, suas ciladas e suas oportunidades. Desse modo estará, efetivamente, escrevendo sua história com a força do sonho, do mito que se torna real por meio do cuidado, pois "tudo o que existe e vive precisa ser cuidado para continuar a existir e

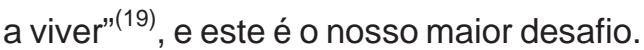

Finalizando, a Estomaterapia demonstra possuir um significado que transcende o tradicional, o comum, o igual, ou seja está trilhando um caminho objetivo e definido, a fim de produzir uma nova representação do ENFERMEIRO na sociedade, contribuindo para o seu reconhecimento como um PROFISSIONAL ÚNICO, FUNDAMENTAL E ESSENCIAL na prática de saúde no país.

9. Santos VLCG. Cuidados avançados em estomaterapia: vislumbrando o 3o milênio. Rev Esc Enfermagem USP 1999 outubro; 33:1-3.

10. Padilha KG. Des-cuidar. As representações dos enfermeiros de UTI sobre as ocorrências iatrogênicas de enfermagem. [tese]. São Paulo (SP): Escola de Enfermagem/ USP; 1994.

11. Campos GWS. O século XX. Glórias e equívocos. Ser médico1999; 2:44-6.

12. Cianciarullo TI. Especialização: a contextualização do futuro da Enfermagem. In: Santos VLCG, Cesaretti IUR, organizadoras. Assistência em estomaterapia: cuidando do ostomizado. São Paulo (SP): Atheneu; 2001.

13. World Council of Enterostomal Therapists - WCET. An association of nurses. Members handbook. Australia: Ink Press International; 2000.

14. Minayo MCS. Pesquisa Social-teoria, método e criatividade. Petrópolis (RJ):Vozes; 1993.

15. Bison RAP. Representações Sociais dos estudantes de Enfermagem sobre sexualidade, numa experiência de ensino. [dissertação] .Ribeirão Preto (SP): Escola de Enfermagem/USP; 1998. 
16. Moscovici S. Prefácio. In: Guareschi P, Jovchelovitch S, organizadores. Textos em Representações Sociais. $2^{\mathfrak{a}}$ ed. Petrópolis (RJ):Vozes; 1995.

17. Henry P, Moscovici S. Problèmes de l'analyse de contenu. $2^{a}$ ed. Paris: Langage; 1968.

18. Bardin L. Análise de Conteúdo. Lisboa : Ed. 70; 1977.

19.Boof L. Saber cuidar: ética do humano - compaixão pela terra. Petrópolis (RJ) :Vozes; 2000. 